\title{
Neutrophil-to-mean platelet volume ratio as a new predictor for overall and cancer-specific survival in patients with localized clear cell renal cell carcinoma
}

\author{
Marcin Życzkowski ${ }^{1}$, Paweł Rajwa ${ }^{1}$, Bartłomiej Burzyński², Maciej Gaździk³ , Iga Florczyk², \\ Monika Slabon-Turska ${ }^{3}$, Andrzej Paradysz ${ }^{1}$
}

\begin{abstract}
'Department of Urology, Medical University of Silesia, Zabrze, Poland ${ }^{2}$ Department of Rehabilitation, School of Health Sciences, Medical University of Silesia, Katowice, Poland

${ }^{3}$ Student Scientific Society, Department of Urology, Medical University of Silesia, Zabrze, Poland
\end{abstract}

Submitted: 4 December 2018

Accepted: 8 February 2019

Arch Med Sci 2020; 16 (5): 1072-1077

DOI: https://doi.org/10.5114/aoms.2019.83822

Copyright $\odot 2019$ Termedia \& Banach

\begin{abstract}
Introduction: The present study investigated the prognostic value of neutrophil-to-mean platelet volume ratio (NMPVR) for overall (OS) and cancer-specific survival (CSS) in patients treated with nephrectomy for localized clear cell renal cell carcinoma (ccRCC).

Material and methods: Medical records of 344 consecutive patients who underwent partial or radical nephrectomy for MO $c C R C C$ were retrospectively analyzed. Based on the median NMPVR, the study population was divided into two groups: the high NMPVR group with NMPVR higher than or equal to the median, and the low NMPVR group with NMPVR lower than the median. Comparisons of baseline characteristics and laboratory and pathological findings were performed. Kaplan-Meier survival curves and Cox regression model analysis were used to assess the prognostic value of the NMPVR.

Results: Patients with higher NMPVR values were more frequently diagnosed with advanced disease, tumor necrosis and higher tumor grade. The OS and CSS were significantly shorter in patients with NMPVR $\geq 0.41$ compared to patients with NMPVR $<0.41$. Inclusion of NMPVR in multivariable models of OS and CSS with other confounding variables determined categorized NMPVR as an independent prognostic factor for both endpoints.

Conclusions: Pretreatment NMPVR $\geq 0.41$ was associated with lower OS and CSS. NMPVR might be applied as a cheap and uncomplicated prognostic indicator in localized cCRCC patients treated with a primary surgical approach.
\end{abstract}

Key words: biomarker, renal cell carcinoma, neutrophil-to-mean platelet volume ratio, neutrophil, platelets.

\section{Introduction}

Being the third most common genitourinary malignancy, renal cell carcinoma (RCC) represents about 3\% of all cancers in adults [1]. The RCC is the seventh most frequent cancer in men and the ninth in women worldwide [2]. Due to a significant improvement in diagnostic radiology, more incidental RCC are observed. However, $25 \%$ of patients with RCC still present metastases at first diagnosis [3]. Numerous risk factors for RCC have been indicated, including cigarette smoking, obesity, cadmi-

\author{
Corresponding author: \\ Maciej Gaździk \\ Student Scientific \\ Society \\ Department of Urology \\ Medical University \\ of Silesia \\ 13-15 3 Maja St \\ 41-800 Zabrze, Poland \\ E-mail: mac.gazdzik@gmail. \\ com
}


um and asbestos intoxication, diabetes mellitus, hypertension and chronic dialysis [4]. Regarding the histological aspect of kidney cancer, it is mostly composed of clear cell RCC (ccRCC), which accounts for over $70 \%$ of RCC cases [5].

In localized RCC, the only high-quality evidenced treatment is surgical resection [4]. Relevant advances in surgical treatment, immunotherapy and targeted therapy in RCC were observed. Nevertheless, long-term outcomes are still not satisfactory, particularly due to common local recurrences, distal metastases and limited drug response [6]. Under those circumstances, an improvement in RCC patients' management could be obtained by developing novel, easily obtainable and cheap prognostic markers which might help select patients who would benefit most from additional postoperative care $[7,8]$. It is commonly known that blood is full of tumor-associated biomarkers, such as pro-inflammatory cells, including neutrophils and platelets. As evidenced by a multitude of research, the systemic inflammatory reaction plays a crucial role in tumorigenesis [9].

Numerous studies have linked neutrophilia with poor prognosis, e.g. in cervical or prostate cancer patients $[10,11]$. Elevated neutrophil count in peripheral blood has been identified as a predictor of shorter overall survival (OS) in metastatic RCC patients [12].

Increased platelet count was associated with poor prognosis in pancreatic, gastric, colorectal, endometrial and ovarian cancers [13-17]. Mean platelet volume (MPV) is a widely used index of platelet activation that has been linked with various inflammatory states [18]. Decreased MPV was associated with decreased survival in non-small cell lung cancer and esophageal cancer patients $[19,20]$. In RCC patients, two studies confirmed MPV as an independent prognostic factor for cancer-specific survival (CSS) [21, 22] and one study proved it to be an independent prognostic factor of OS [23].

Up to now, there are no studies that have used both blood cell parameters as predictive factors in RCC, or in any other cancer. That is the reason why we attempted to evaluate the influence of neutrophil-to-mean platelet volume ratio (NMPVR) on OS and CSS in patients treated with radical or partial nephrectomy for localized (MO) ccRCC.

\section{Material and methods}

In this retrospective study, we analyzed 344 who underwent partial or radical nephrectomy for MO cCRCC at our institution between January 2003 and December 2012. The NMPVR was calculated as neutrophil count divided by mean platelet volume. Information on survival was obtained from the Polish Ministry of Interior and Administration, which stores, among other data, the exact date of death of every Polish citizen since the mid-1980s. Cause of death was accessed from the Polish National Cancer Registry and the National Health Fund. Complete follow-up data were available for all analyzed patients.

\section{Statistical analysis}

Quantitative data are presented as medians and interquartile ranges. Qualitative data are presented as frequencies. Comparisons of baseline characteristics and laboratory and pathological findings were performed using the Mann-Whitney $U$ test and the $\chi^{2}$ test, where appropriate. Based on the median NMPVR, the study population was divided into two groups: the high NMPVR group with NMPVR higher than or equal to the median, and the low NMPVR group with NMPVR lower than median. Differences in overall and cancer-specific survival between groups were compared using the Kaplan-Meier method and log-rank test. The Cox proportional hazards regression model was applied to perform univariate and multivariate analyses. Variables with a $p$-value lower than 0.05 in univariate analysis were subjected to multivariable analysis. Statistical analyses were performed using the Statistica 13.1 software with the Medical Bundle (StatSoft Inc., Tulsa, Oklahoma, USA).

\section{Results}

The median follow-up was 2184 (interquartile range: 1553-3243) days. During the observation period both overall and cancer-specific survival rates were higher in patients with low NMPVR than in patients with high NMPVR (Table I, Figures $1,2)$. Comparison of baseline characteristics and laboratory and pathological findings across groups of patients with low and high NMPVR who underwent nephrectomy due to localized ccRCC is presented in Table I. Briefly, there were no significant differences between patients with high and low NMPVR in terms of sex, age, lymph node involvement and sarcomatoid feature presence. Patients with higher NMPVR values were more often diagnosed with advanced disease, tumor necrosis and higher tumor grade. This group also underwent radical nephrectomy more frequently. The NMPVR was significantly associated with overall survival and cancer-specific survival, both in univariate and in multivariate analysis, after adjustment for clinicopathological covariates (Table II).

\section{Discussion}

Until now, there have been no studies recognizing the new blood-based biomarker NMPVR as a prognostic factor either in RCC or in any other neoplasm. Our study is the first one to determine 
Table I. Comparison of baseline characteristics, laboratory and pathological findings across groups of patients with low and high NMPVR values

\begin{tabular}{|c|c|c|c|}
\hline \multirow[t]{2}{*}{ Parameter } & \multicolumn{3}{|c|}{ NMPVR } \\
\hline & $\begin{array}{c}\text { Low }(<0.41) \\
(n=172)\end{array}$ & $\begin{array}{l}\text { High }(\geq 0.41) \\
\quad(n=172)\end{array}$ & $P$-value \\
\hline Sex: & & & 0.08 \\
\hline Male & $46 \%$ & $55 \%$ & \\
\hline Female & $54 \%$ & $45 \%$ & \\
\hline Age [years] & $64.0(55.0-71.0)$ & $62.0(54.0-69.0)$ & 0.2 \\
\hline BMI $\left[\mathrm{kg} / \mathrm{m}^{2}\right]$ & $27.2(24.5-30.7)$ & $27.1(24.6-30.2)$ & 0.82 \\
\hline Hemoglobin [g/dl] & $13.7(12.8-14.7)$ & $13.9(12.4-15.1)$ & 0.71 \\
\hline Red blood cell count $\left[\times 10^{6} / \mathrm{mm}^{3}\right]$ & $4.47(4.25-4.77)$ & $4.61(4.29-4.9)$ & 0.11 \\
\hline White blood cell count $\left[\times 10^{6} / \mathrm{mm}^{3}\right]$ & $5.6(5.0-6.4)$ & $8.0(6.8-9.1)$ & $<0.0001$ \\
\hline Lymphocytes $\left[\times 10^{3} / \mathrm{mm}^{3}\right]$ & $1.9(1.5-2.4)$ & $1.9(1.6-2.5)$ & 0.26 \\
\hline Neutrophils $\left[\times 10^{3} / \mathrm{mm}^{3}\right]$ & $3.1(2.5-3.6)$ & $5.0(4.1-5.9)$ & $<0.0001$ \\
\hline Monocytes $\left[\times 10^{3} / \mathrm{mm}^{3}\right]$ & $0.4(0.3-0.5)$ & $0.5(0.4-0.6)$ & $<0.0001$ \\
\hline Platelets $\left[\times 10^{3} / \mathrm{mm}^{3}\right]$ & $219.0(175.0-260.0)$ & $267.0(220.0-330.0)$ & $<0.0001$ \\
\hline MPV [fl] & $10.4(9.0-11.8)$ & $8.5(7.7-9.8)$ & $<0.0001$ \\
\hline Sarcomatoid feature: & & & 0.39 \\
\hline Present & $1 \%$ & $2 \%$ & \\
\hline Absent & $99 \%$ & $98 \%$ & \\
\hline pT stage: & & & 0.009 \\
\hline $\mathrm{pT} 1 / \mathrm{pT} 2$ & $84 \%$ & $72 \%$ & \\
\hline pT3/pT4 & $16 \%$ & $28 \%$ & \\
\hline Lymph node involvement: & & & 0.54 \\
\hline pNO & $97 \%$ & $96 \%$ & \\
\hline $\mathrm{pN} 1$ & $3 \%$ & $4 \%$ & \\
\hline TNM stage: & & & 0.003 \\
\hline 1 & $73 \%$ & $55 \%$ & \\
\hline II & $10 \%$ & $15 \%$ & \\
\hline III & $17 \%$ & $29 \%$ & \\
\hline IV & $0 \%$ & $1 \%$ & \\
\hline Tumor grade: & & & 0.005 \\
\hline $\mathrm{G} 1 / \mathrm{G} 2$ & $77 \%$ & $63 \%$ & \\
\hline G3/G4 & $23 \%$ & $37 \%$ & \\
\hline Tumor size $[\mathrm{mm}]$ & $45.0(35.0-60.0)$ & $60.0(40.0-75.0)$ & 0.001 \\
\hline Nephrectomy: & & & 0.04 \\
\hline Partial & $39 \%$ & $28 \%$ & \\
\hline Radical & $61 \%$ & $72 \%$ & \\
\hline Tumor necrosis: & & & 0.04 \\
\hline Present & $11 \%$ & $19 \%$ & \\
\hline Absent & $89 \%$ & $81 \%$ & \\
\hline Overall survival & $68 \%$ & $58 \%$ & $0.002^{*}$ \\
\hline Cancer-specific survival & $86 \%$ & $77 \%$ & $0.006^{*}$ \\
\hline
\end{tabular}

*log-rank. Continuous variables are presented as median (interquartile range). Dichotomous variables are presented as percentages. $B M I$ - body mass index, MPV - mean platelet volume, NMPVR - neutrophil-to-mean platelet volume ratio. 


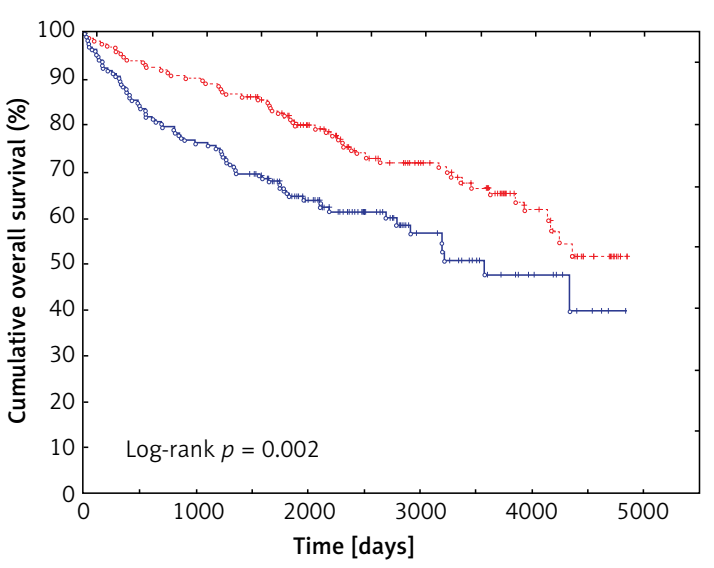

- High NMPVR - - Low NMPVR

Figure 1. Kaplan-Meier curves for overall survival of cCRCC patients with high and low NMPVR

NMPVR - neutrophil-to-mean platelet volume ratio, CCRCC - clear cell renal cell carcinoma.

the prognostic value of NMPVR in patients suffering from cancer. We demonstrated that neutrophil-to-mean platelet volume ratio was an independent prognostic factor for both cancer-specific and overall survival of RCC patients undergoing radical or partial nephrectomy. In addition, the group with baseline NMPVR $\geq 0.41$ was more likely to be treated with radical nephrectomy and has more advanced disease, with higher prevalence of tumor necrosis and a higher Fuhrman grade.

Many papers have raised the topic of neutrophilia as a prognostic marker in several cancers, including RCC [10-12]. Donskov et al. identified increased neutrophil count of over $6 \times 10^{9} / \mathrm{l}$ in peripheral blood as an independent predictor for shorter OS in RCC patients. However, contrary to our study, their study group was treated with IL-2 based immunotherapy and patients presented metastases [12].

Three studies recognized MPV as a possible predictor of survival in RCC patients treated sole-

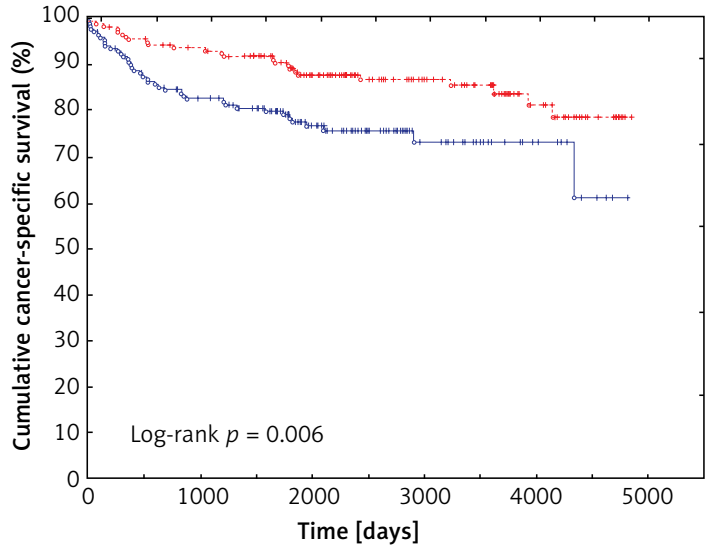

— High NMPVR -.- Low NMPVR

Figure 2. Kaplan-Meier curves for cancer-specific survival of cCRCC patients with high and low NMPVR

NMPVR - neutrophil-to-mean platelet volume ratio, CCRCC - clear cell renal cell carcinoma.

ly surgically. Seles et al. defined MPV lower than $9.5 \mathrm{fl}$ as a negative prognostic factor for CSS [22]. Prokopowicz et al. proposed the MPV cut-off value as $10.1 \mathrm{fl}$, given that patients with lower values suffered from significantly higher cancer-specific mortality [21]. Yun et al. discovered that patients with MPV lower than $7.5 \mathrm{fl}$ had shorter OS [23].

Even though it has not been examined before, we hypothesize that NMPVR might be utilized in oncology, as it simultaneously evaluates two independent cellular lines involved in inflammatory processes, namely neutrophils and platelets. It has been proven that not only the tumor's oncological characteristics have an impact on the outcome, but also the host's inflammatory response to a progressing malignancy [24]. Mechanisms involved in the interactions between cancer and inflammation are complicated - inflammation impacts every single step of tumorigenesis, from tumor initiation to promotion and metastasis formation [9].

Table II. Prognostic value of NMPVR in patients with localized ccRCC who underwent nephrectomy - univariate and multivariate analyses

\begin{tabular}{|c|c|c|c|}
\hline Parameter & HR & $95 \% \mathrm{Cl}$ & $P$-value \\
\hline \multicolumn{4}{|l|}{ Overall mortality: } \\
\hline Univariate analysis & 3.4 & $2.16-5.47$ & $<0.0001$ \\
\hline Multivariate analysis* & 2.24 & $1.4-3.59$ & 0.0008 \\
\hline \multicolumn{4}{|l|}{ Cancer-specific mortality: } \\
\hline Univariate analysis & 3.74 & $2.18-6.61$ & $<0.0001$ \\
\hline Multivariate analysis** & 2.02 & $1.08-3.77$ & 0.03 \\
\hline
\end{tabular}

${ }^{*}$ Adjusted for age ( $\left.\geq 65 /<65\right)$, pT stage, nephrectomy (partial/radical), sarcomatoid feature, presence of tumor necrosis, tumor grade, lymph node involvement. ${ }^{* *}$ Adjusted for age $(\geq 65 /<65)$, pT stage, nephrectomy (partial/radical), presence of tumor necrosis, tumor grade, lymph node involvement. cCRCC - clear cell renal cell carcinoma, HR - hazard ratio, Cl - confidence interval, NMPVR - neutrophil-to-mean platelet volume ratio. 
It has been demonstrated that neutrophil count increases in relation to the systemic inflammatory response against the tumor [25]. Expression of NF$\kappa \mathrm{B}$, STAT3 and KIF1 $\alpha$ transcription factors in tumor cells contributes to an increase in concentration of several cytokines (IL-1, IL-6, IL-8 and IFN- $\gamma$ ), leading to neutrophil recruitment and their upsurge in peripheral blood. Neutrophils release reactive oxygen species which damage DNA and may lead to promotion of tumor development [26-28]. Additionally, neutrophils produce inflammatory (e.g. IL-1, IL-6, IL-8) and proangiogenic cytokines (e.g. epidermal growth factor (EGF) and vascular endothelial growth factor (VEGF)), facilitating malignant disease development and metastases [29, 30].

Platelets play a crucial role in tumor progression, angiogenesis and metastasis by directly interacting with tumor cells, promoting their proliferation as well as the secretion of angiogenic and mitogenic proteins, including VEGF, PDGF, thrombospondins, endostatins and hepatocyte growth factors [31-33]. Circulating tumor cells (CTCs) lead to activation and aggregation of platelets, which correlate with their metastatic potential. Platelets shield CTCs from immune cells and cytotoxicity mediated by TNF- $\alpha$. Consequently, there exists specific reciprocal feedback between platelets and tumor cells' activity [34]. The MPV was recognized as one of the first markers of platelet activation. Furthermore, decreased MPV is linked with excessive degradation of large platelets in severe inflammatory diseases, which could be reversed in the course of anti-inflammatory therapy [18].

We are aware that the present paper is not without limitations. Firstly, our study was single-centered and retrospective in nature. Secondly, we were not able to obtain postoperative therapy data. Thirdly, our study population consisted of Polish citizens only. The application to other ethnic groups still needs further investigation. Larger prospective randomized studies are needed to validate and extend our findings.

In conclusion, our study has revealed that NMPVR may be used in everyday urological practice as a cheap and easily obtainable prognostic marker for OS and CSS in patients with localized ccRCC. It might be used to identify patients who would benefit most from additional, more intense postoperative care.

\section{Conflict of interest}

The authors declare no conflict of interest.

\section{References}

1. Bhatt JR, Finelli A. Landmarks in the diagnosis and treatment of renal cell carcinoma. Nat Rev Urol 2014; 11: $517-25$.
2. Chow WH, Dong LM, Devesa SS. Epidemiology and risk factors for kidney cancer. Nat Rev Urol 2010; 7: 245-57.

3. Vogl UM, Zehetgruber H, Dominkus M, et al. Prognostic factors in metastatic renal cell carcinoma: metastasectomy as independent prognostic variable. Br J Cancer 2006; 95: 691-8.

4. Ljungberg B, Bensalah K, Canfield S, et al. EAU guidelines on renal cell carcinoma: 2014 update. Eur Urol 2015; 67: 913-24.

5. Inamura K. Renal cell tumors: understanding their molecular pathological epidemiology and the 2016 WHO classification. Int J Mol Sci 2017; 18: 15-20.

6. Siegel R, Naishadham D, Jemal A. Cancer statistics, 2013. CA Cancer J Clin 2013; 63: 11-30.

7. Rajwa P, Życzkowski M, Paradysz A, et al. Novel hematological biomarkers predict survival in renal cell carcinoma patients treated with nephrectomy. Arch Med Sci 2020; 15: 1062-71.

8. Jędroszka D, Orzechowska M, Bednarek A. Predictive values of Notch signalling in renal carcinoma. Arch Med Sci 2017; 13: 1249-54.

9. Grivennikov SI, Greten FR, Karin M. Immunity, inflammation, and cancer. Cell 2011; 140: 883-99.

10. Escande A, Haie-Meder C, Maroun P, et al. Neutrophilia in locally advanced cervical cancer: a novel biomarker for image-guided adaptive brachytherapy? Oncotarget 2016; 7: 74886-94.

11. Kwon YS, Han CS, Yu JW, et al. Neutrophil and lymphocyte counts as clinical markers for stratifying low-risk prostate cancer. Clin Genitourin Cancer 2016; 14: e1-8.

12. Donskov F, Von Der Maase H. Impact of immune parameters on long-term survival in metastatic renal cell carcinoma. J Clin Oncol 2006; 24: 1997-2005.

13. Suzuki K, Aiura K, Kitagou M. Platelets counts closely correlate with the disease-free survival interval of pancreatic cancer patients. Hepatogastroenterology 2004; 51: 847-53.

14. Ekici H, Malatyalioglu E, Kokcu A, Kurtoglu E, Tosun M, Celik H. Do leukocyte and platelet counts have benefit for preoperative evaluation of endometrial cancer? Asian Pacific J Cancer Prev 2015; 16: 5305-10.

15. Pietrzyk L, Plewa Z, Denisow-Pietrzyk M, Zebrowski R, Torres K. Diagnostic power of blood parameters as screening markers in gastric cancer patients. Asian Pacific J Cancer Prev 2016; 17: 4433-7.

16. Qiu J, Yu Y, Fu Y, Ye F, Xie X, Lu W. Preoperative plasma fibrinogen, platelet count and prognosis in epithelial ovarian cancer. J Obstet Gynaecol Res 2012; 38: 651-7.

17. Long Y, Wang T, Gao Q, Zhou C. Prognostic significance of pretreatment elevated platelet count in patients with colorectal cancer: a meta-analysis. Oncotarget 2016; 7: 81849-61.

18. Gasparyan AY, Ayvazyan L, Mikhailidis DP, Kitas GD. Mean platelet volume: a link between thrombosis and inflammation? Curr Pharm Des 2011; 17: 47-58.

19. Inagaki N, Kibata K, Tamaki T, Shimizu T, Nomura S. Prognostic impact of the mean platelet volume/platelet count ratio in terms of survival in advanced non-small cell lung cancer. Lung Cancer 2014; 83: 97-101.

20. Shen W, Cui MM, Wang X, Wang RT. Reduced mean platelet volume is associated with poor prognosis in esophageal cancer. Cancer Biomark 2018; 22: 559-63.

21. Prokopowicz G, Życzkowski M, Nowakowski K, Bogacki R, Bryniarski P, Paradysz A. Basic parameters of blood count as prognostic factors for renal cell carcinoma. Biomed Res Int 2016; 2016: 8687575.

22. Seles M, Posch F, Pichler GP, et al. Blood platelet volume represents a novel prognostic factor in patients with 
nonmetastatic renal cell carcinoma and improves the predictive ability of established prognostic scores. J Urol 2017; 198: 1247-52.

23. Yun Z, Zhang X, Liu Y, et al. Lower mean platelet volume predicts poor prognosis in renal cell carcinoma. Sci Rep 2017; 7: 6700.

24. MacDonald N. Cancer cachexia and targeting chronic inflammation: a unified approach to cancer treatment and palliative/supportive care. J Support Oncol 2007; 5: 157-62.

25. Zahorec R. Ratio of neutrophil to lymphocyte counts: rapid and simple parameter of systemic inflammation and stress in critically ill. Bratisl Lek Listy 2001; 102: 5-14.

26. Mantovani A, Allavena P, Sica A, Balkwill F. Cancer-related inflammation. Nature 2008; 454: 436-44.

27. Templeton AJ, McNamara MG, Šeruga B, et al. Prognostic role of neutrophil-to-lymphocyte ratio in solid tumors: a systematic review and meta-analysis. J Natl Cancer Inst 2014; 106: dju124.

28. Muller I, Munder M, Kropf P, Hansch GM. Polymorphonuclear neutrophils and $T$ lymphocytes: strange bedfellows or brothers in arms? Trends Immunol 2009; 30: 522-30.

29. Grivennikov SI, Greten FR, Karin M. Immunity, inflammation, and cancer. Cell 2010; 140: 883-99.

30. Tian Y, Li M, Wu S, et al. Neutrophil elastase stimulates MUC5AC expression in human biliary epithelial cells: a possible pathway of PKC/Nox/ROS. Arch Med Sci 2017; 13: 677-85.

31. Kubes P. The versatile platelet contributes to inflammation, infection, hemostasis, coagulation and cancer. Semin Immunol 2016; 28; 535.

32. Mezouar S, Frère C, Darbousset R, et al. Role of platelets in cancer and cancer-associated thrombosis: experimental and clinical evidences. Thromb Res 2016; 139: 65-76.

33. Verheul HM, Jorna AS, Hoekman K, Broxterman HJ, Gebbink MF, Pinedo HM. Vascular endothelial growth factor-stimulated endothelial cells promote adhesion and activation of platelets. Blood 2000; 96: 4216-21.

34. Menter DG, Tucker SC, Kopetz S, Sood AK, Crissman JD, Honn KV. Platelets and cancer: a casual or causal relationship: revisited. Cancer Metastasis Rev 2014; 33: 231-69. 